Proceedings of the 2011 Winter Simulation Conference

S. Jain, R.R. Creasey, J. Himmelspach, KP. White, and M. Fu, eds.

\title{
RSB TOOL: \\ A LCA TOOL FOR THE ASSESSMENT OF BIOFUELS SUSTAINABILITY
}

\author{
Jürgen Reinhard \\ Mireille Faist Emmenegger \\ Empa, Material Science and Technology \\ Überlandstrasse 129 \\ CH-8600 Dübendorf, SWITZERLAND
}

\author{
Andi H. Widok \\ Volker Wohlgemuth \\ HTW-Berlin, University of Applied Sciences \\ Wilhelminenhofstrasse 75A \\ D-12459 Berlin, GERMANY
}

\begin{abstract}
The paper focuses on the role of simulation within the RSB GHG Tool, which is a web-based decision support tool that assesses greenhouse gas emissions of biofuels according to the principles of the Roundtable on Sustainable Biofuels. Using a questionnaire, each operator can specify his individual data and calculate the GHG emission for his production step. To derive the environmental flows required for the impact assessment, the tool applies simulation, which allows generating a full inventory on the basis of the limited input data the operator can provide. This is the basis for the interactive assessment of the GHG emissions of individual steps of biofuels pathways, without the need of conducting a time and resourceintensive Life Cycle Assessment study. In this paper, we focus on the simulation for the emissions caused by land use change since such emissions can play a dominating role in the GHG balance of a biofuel.
\end{abstract}

\section{INTRODUCTION}

A major driver for the current political support of the biofuels market is their supposed environmental benefits. Biofuels appear to be carbon neutral, while decreasing the dependence from oil-producing regions and generating new income for farmers (IEA 2007). However, results from current life-cycle studies demonstrate that greenhouse gas savings of conventional biofuels are usually small due to the carbon intensity of the cultivation and fuel production (Farrell, Plevin et al. 2006; Zah, Hischier et al. 2007) and the overall balance of environmental impacts like ecotoxicity, eutrophication or biodiversity loss can show unfavorable results for biofuels when compared to fossil fuels (Scharlemann and Laurance 2008). Moreover, the negative effects of biofuels are strongly dominating if carbon and biodiversity loss due to direct (Fargione, Hill et al. 2008) and indirect (Searchinger, Heimlich et al. 2008; Reinhard and Zah 2009) land transformation are considered in the full life cycle of biofuels. Certification schemes could be an effective approach for ensuring the sustainable production of biofuels by keeping environmental impacts within certain limits (Zah, Faist et al. 2009).

Nowadays, various legislation or certification schemes are already realized or in development, such as the Californian Low Carbon Fuel Standard (LCFS) (CARB 2009), the Renewable Fuel Standard (RFS2) (EPA 2010), the UK Renewable Transportation Fuel Obligation (RTFO) (Bauen, Watson et al. 2007; Dehue, Hamelinck et al. 2007), the Swiss mineral oil tax redemption for sustainable biofuels (Leuenberger and Huber-Hotz 2006), the European CEN-standard (TC383 2009), or the Roundtable on Sustainable Biofuels (RSB 2008). In addition to the assessment of sustainability based on principles and criteria, those regulations often require calculations of greenhouse gas (GHG) emissions or even of environmental impacts (Swiss regulation) on the basis of Life Cycle Assessment (LCA). In general, environmental impacts occur in all stages of the biofuels value chain, by transforming the land needed, by producing and applying fertilizers or pesticides, by use of agricultural machinery, by producing the biofuel, by transporting it 


\section{Reinhard, Faist Emmenegger, Widok and Wohlgemuth}

to the gauging station and by using it in transportation devices. Consequently, the adequate assessment of environmental impacts along the life cycle of biofuels is a resource intensive and complex task and even more complicated is the assessment of their overall sustainability (Zah, Faist et al. 2009).

The goal of this project was to develop a web-based tool for the interactive evaluation of biofuels sustainability according to the certification scheme of the RSB. In this paper we describe the role of simulation in the RSB GHG module, which has been developed as a specific module within the RSB Tool. It allows the modular assessment of GHG emissions for numerous biofuel pathways with different methodologies: RSB, EU Renewable Energy Directive (EU RED), Ordinance on mineral oil tax (CH), Low Carbon Fuel Standard (LCFS/USA), and U.S. Renewable Fuel Standard (RFS2/USA). We focus on the simulation for the calculation of the emissions caused by Land Use Change (LUC) since such emissions can play a dominating role in the GHG balance of a biofuel.

\section{THE RSB TOOL}

The Roundtable on Sustainable Biofuels (RSB) is an international initiative coordinated by the Energy Center at EPFL in Lausanne that brings together farmers, companies, non-governmental organizations, experts, governments, and inter-governmental agencies concerned with ensuring the sustainability of biofuels production and processing. The RSB has developed a third-party certification system for biofuels sustainability standards, encompassing environmental, social and economic principles and criteria through an open, transparent, and multi-stakeholder process.

The RSB Tool has been developed in this project so as to enable operators to verify compliance with all applicable standards of the RSB certification system and with regulatory requirements of the markets, for which a specific biofuel is intended for. Here and in the following we define an operator as a producer in the chain of biofuel who uses the RSB Tool. To verify his compliance an operator needs to perform a self-assessment with respect to the RSB Standard, including the RSB Principles and Criteria (P\&C) as well as a Risk Assessment and the RSB GHG calculation.

The RSB GHG module computes GHG emissions with different methodologies, compliance with EU RED, and other GHG regulations (such as CA LCFS, US RFS). The main functions of the GHG tool can be summarized as follows:

- stepwise calculations of GHG intensity of a biofuel,

- possibility of applying different regulations / schemes,

- use of default data to complete the fuel chain,

- possibility of integrating data of other operators and

- integration of water use.

As prior mentioned, this paper will focus exclusively on the general principles and the role of simulation in the RSB GHG module.

\section{TOOL STRUCTURE}

\subsection{Methodological Framework}

The Life Cycle Assessment (LCA) framework provides the basis for the concept and workflow of the RSB GHG module. LCA is a technique for assessing the environmental impacts of a given product or service over its life cycle, i.e. from cradle-to-grave (Guinée 2001). It comprises the compilation and the evaluation of the inputs, outputs and potential environmental impacts of a product system throughout its life cycle (Guinée 2001). In practice, the LCA framework consists of four basic steps.

1. Goal and scope definition: Here the fundamental direction of the LCA is defined including the purpose of the study as well as the general condition. The scoping process links the goal of the LCA with the extent of the study, which defines what will or will not be included (Schaltegger 1996). This first step provides a description of the product system in terms of the system bounda- 


\section{Reinhard, Faist Emmenegger, Widok and Wohlgemuth}

ries and a functional unit, which enables alternative goods, or services, to be compared and analyzed (Rebitzer, Ekvall et al. 2004).

2. Life Cycle Inventory (LCI) Analysis: An LCI can be described as a model of one or more product systems (Rebitzer, Ekvall et al. 2004), which are composed of unit processes, where each process represents one or several activities, such as production processes, transport, or use (Rebitzer, Ekvall et al. 2004). The LCI Analysis aims at identifying and quantifying all inputs and outputs associated with the product system including materials, energy and residuals (Finnveden, Hauschild et al. 2009).

3. Life Cycle Impact Assessment (LCIA): LCIA is a quantitative and/or qualitative process which classifies and characterizes and/or assess the effects of the inputs (resources) and the outputs (emissions) listed in the inventory table (Schaltegger 1996). The LCIA aims at understanding and evaluating the magnitude and significance of the potential environmental impacts of the studied system (Finnveden, Hauschild et al. 2009).

4. In the last step, the interpretation, the results from the previous phases are evaluated in relation to the goal and scope in order to reach conclusions and recommendations (Finnveden, Hauschild et al. 2009).

\subsection{Simulation of Product Systems}

Today, the model of a product system is typically seen as a static simulation model, i.e. it is composed of linearly linked unit processes. For each unit process, data of the inputs of natural resources, energy and material flows and the outputs of products, emissions and waste flows is recorded (Rebitzer, Ekvall et al. 2004). The product system can be separated into a foreground and a background system (Figure 1).

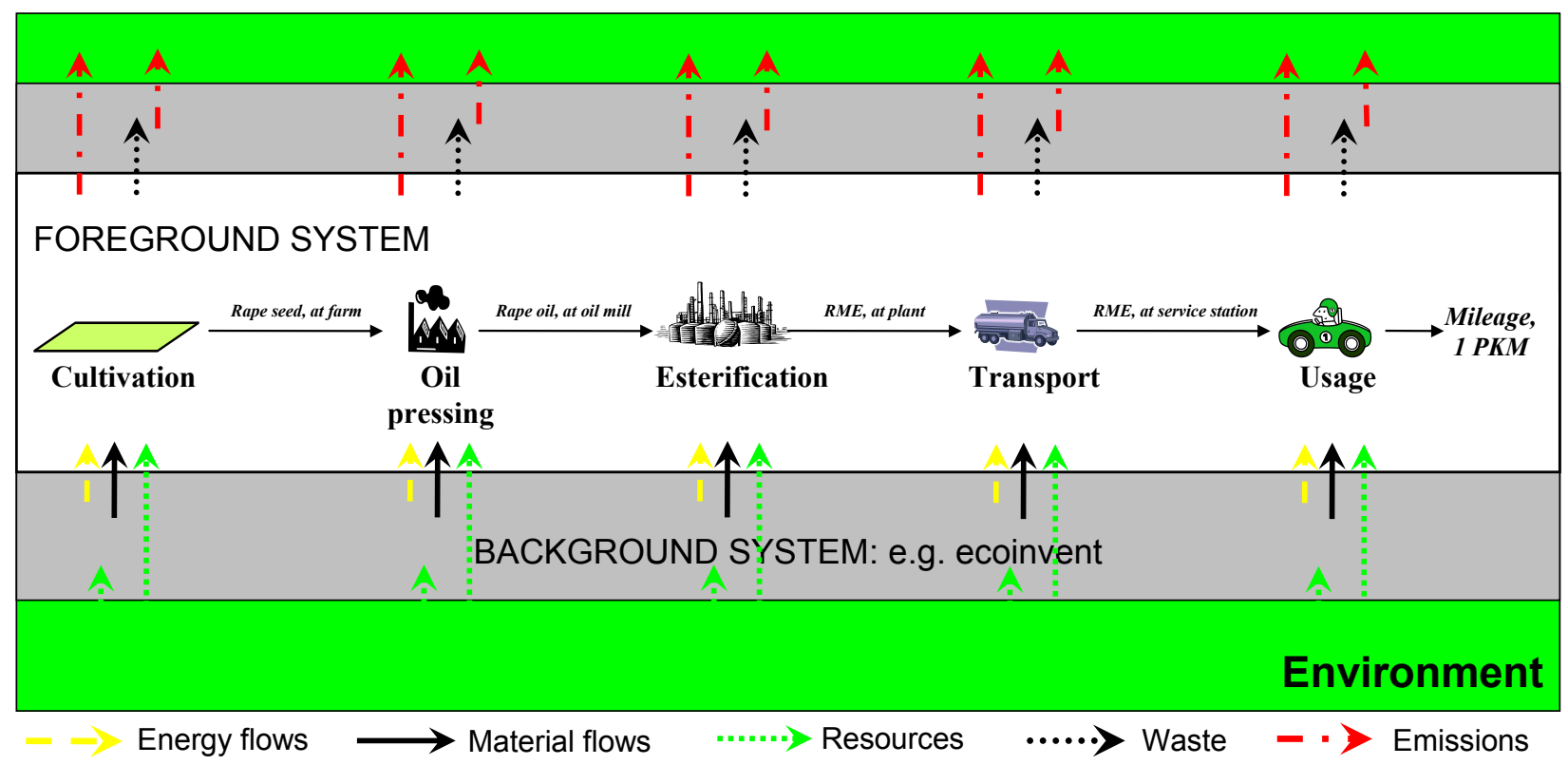

Figure 1: Simplified product system of an exemplary biofuel pathway (source: own depiction).

The foreground system is the collection of processes on which measures may be taken concerning their mode of operation as a result of decisions based on the study (Tillman 2000). The background system consists of all other modeled processes influenced by measures taken in the foreground system (Tillman 2000). This typically implies that material and energy flows of upstream supply are fully elastic. In other words, the induced demand for one unit of a product in the foreground system leads to the production and supply of one unit of product in the background system (Rebitzer, Ekvall et al. 2004). 


\section{Reinhard, Faist Emmenegger, Widok and Wohlgemuth}

The background system usually represents the aggregated data from LCI databases such like ecoinvent (Weidema, Bauer et al. 2011). For example, the foreground system of a generic biofuel LCA encompasses all unit processes directly associated with the production and use of the biofuel, e.g. cultivation of the feedstock, its processing to a biofuel, up to its use (see Figure 1). The background system includes all LCI affected by the measures taken in the foreground system, e.g. the production and provision of the respective amount of fertilizers, pesticides, electricity and machinery which is required for the cultivation of the feedstock.

The boundary between the background system and the natural environment shown in Figure 1 also reflects the boundary between the technosphere and the natural environment. In this perspective, the foreground system transforms the direct inputs from the technosphere (energy and material flows) and the environment (resources) into emissions, waste and product flows. Via the technosphere, the waste and product flows are transformed into emissions or recycled to other product systems. Ultimately, the product system consists of elementary flows from (resources) and to (emissions) the natural environment.

\subsection{Workflow}

Figure 2 shows how the LCA framework described above was implemented in the RSB GHG module.

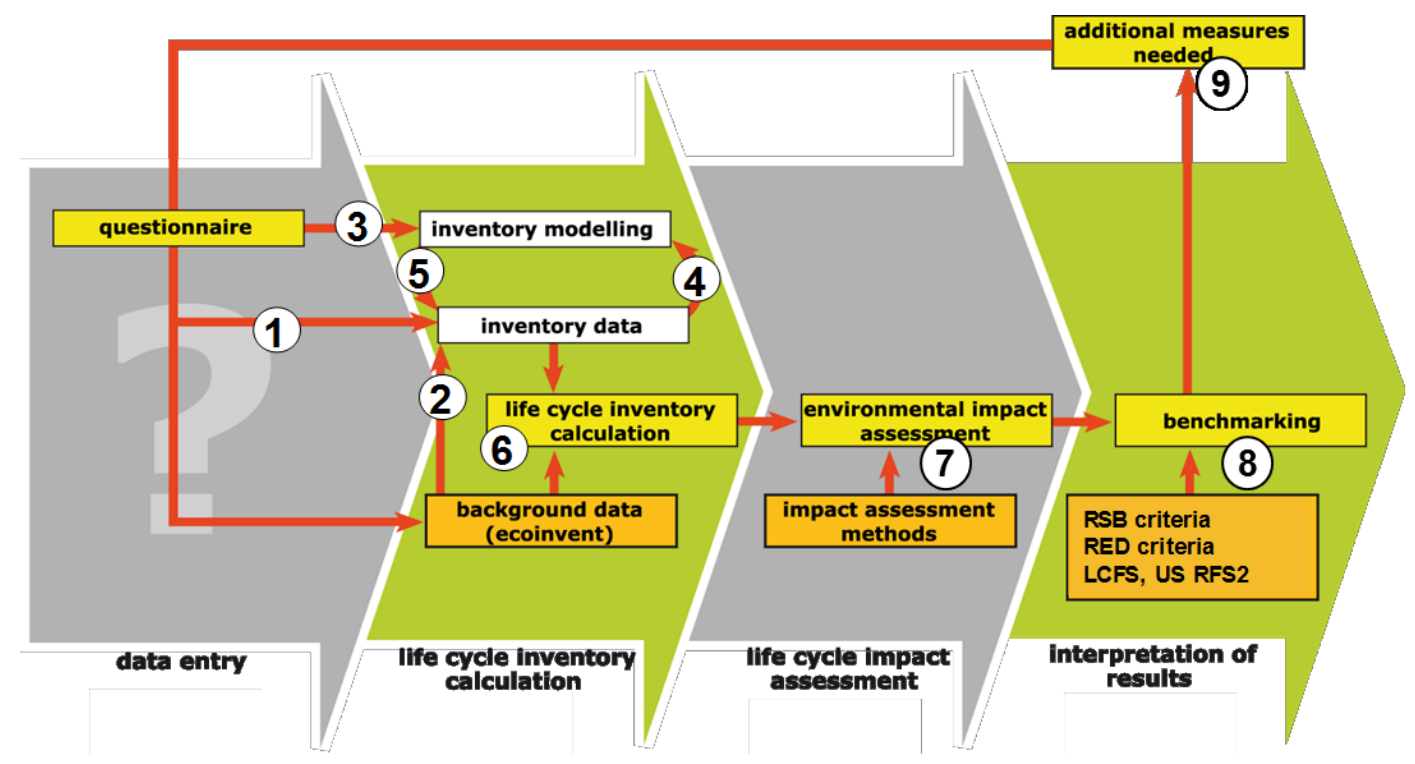

Figure 2: Workflow of environmental impact modeling in the RSB GHG module (source: own depiction).

As shown in Figure 2, an interactive online questionnaire sets the scope of the analysis and gains the data to generate the LCI. The operator can adapt all data directly related to the biofuel pathway, whereas the background data can only be influenced indirectly, i.e. by measures taken in that foreground system.

The compilation of questionnaire data into Life Cycle Inventory (LCI) data uses different paths. Some of the data entered by the operator can be directly used as LCI flows (step 1). The greatest part of LCI data (step 5) is the result from simulation (3) based on the input data from the operator or (step 4) already determined LCI flows. When all required LCI flows are completed, the final LCI is calculated (step 6). This LCI is the basis for the Life Cycle Impact Assessment (LCIA) (step 7), i.e. the assessment of the environmental impacts inherent to the flows listed in the LCI with regard to Global Warming Potential (GWP). The resulting impacts are benchmarked against the fossil comparator (step 8). The operator can explore the results graphically or by means of tables. If required, he can adapt certain data entries and interactively explore the resulting change in impacts (step 9). 


\subsection{Simulation}

Using simulation allows to generate a full LCI on the basis of the input data the operator can provide. Typically, the operator knows the key factors of the agricultural and technical processes but not the corresponding environmental flows. In other words, there is a gap between the data required for a full LCI and the data known by the operator. For example, a farmer knows in detail the type and amount of fertilizers he is applying and the respective yield of his cultivation; however, he usually does not know the amount of phosphate leaching to the groundwater or the diffusion rate of $\mathrm{N}_{2} \mathrm{O}$ from his field into the atmosphere. This highlights the importance of including simulation in the RSB GHG module in order to combine the specific data of the operator (e.g. land use at reference date, crop yield, etc.) with the context of his system (e.g. ecozone, soil type, etc.) to derive the environmental flows which are required for the impact assessment. In this perspective, simulation is a method for modeling and computer supported analysis of its behaviour with the goal of assessing the impact of different model parameter constellations (Wohlgemuth 2005).

In the following, we will focus on the simulation for the calculation of the emissions caused by land use change (LUC) since such emissions can play a dominating role in the GHG balance of a biofuel. The most important GHG emissions in the context of LUC are $\mathrm{CO}_{2}, \mathrm{~N}_{2} \mathrm{O}$ (di-nitrogen monoxide) and $\mathrm{CH}_{4}$ (methane) (IPCC 2006).

\section{SIMULATION OF EMISSIONS FROM LAND USE CHANGE}

\subsection{Model for Land Use Change (LUC)}

The RSB methodology for the calculation of LUC is primarily based on the IPCC-guidelines (IPCC 2006). The RSB methodology covers the transformation of natural ecosystems to biofuel systems as well as the transformation of managed ecosystems to biofuel systems. In brief, the model calculates the difference between the carbon stored in the land use at reference data (01.01.2009) and the projected land use (Figure 3).

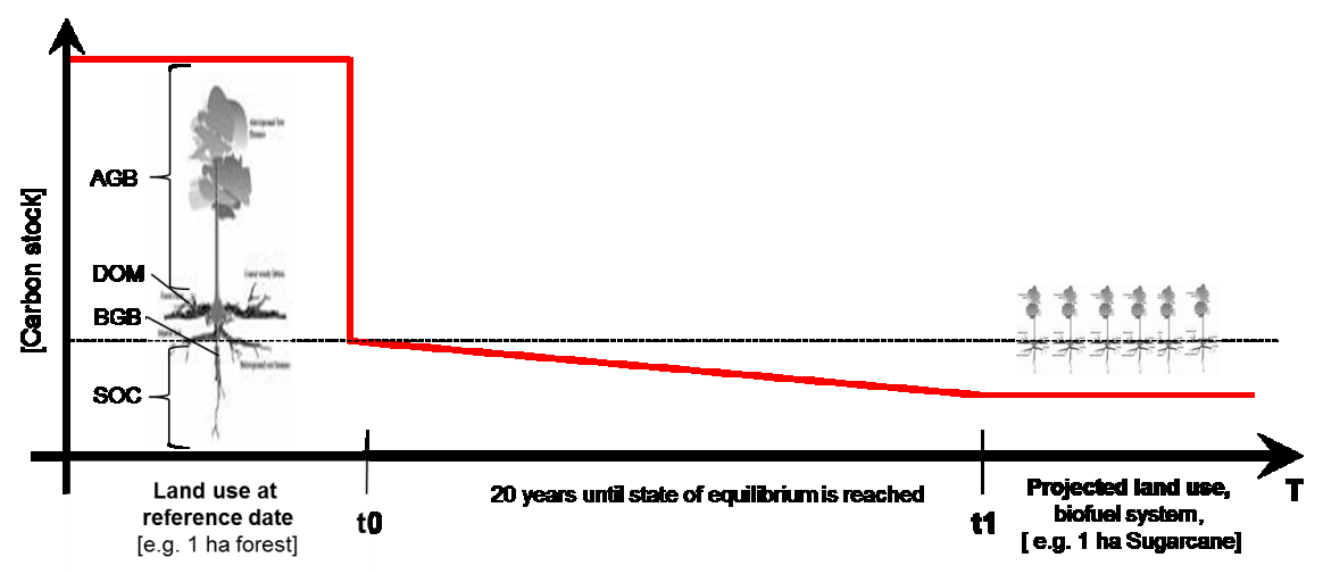

Figure 3: Exemplary change in carbon stock induced by the transformation of forest land to sugarcane (source: own depiction).

The IPCC does not only provide the model but also default values for its application on a global scale. This includes the carbon content for the considered carbon pools and the parameters changing them in dependence on external events. The relevant carbon pools are:

- above ground biomass (AGB) and below ground biomass (BGB) 
- dead organic matter (DOM) and

- soil organic carbon (SOC).

As shown by Figure 3, the exemplary transformation of forest land to sugarcane is associated with a direct loss of AGB, BGB and DOM (t0) and a continuous loss of SOC over 20 years until a new state of equilibrium in SOC is reached ( $\mathrm{t} 1$ ). In general, the method provides the possibility to take into account the GHG emissions $\left(\mathrm{CO}_{2}, \mathrm{~N}_{2} \mathrm{O}\right.$ and $\left.\mathrm{CH}_{4}\right)$ associated with the slashing and burning of the biomass that occurred on the reference land use. If no specific information on slashing and burning is available, the carbon stored in the biomass is assumed to be released to the atmosphere as $\mathrm{CO}_{2}$. It also provides default values for the growth (carbon accumulation) of AGB and BGB on the projected land use. Moreover, it allows the calculation of the decrease / increase in SOC associated with the change in cultivation practice and the $\mathrm{N}_{2} \mathrm{O}$ emissions resulting from the simultaneous mineralization of $\mathrm{N}$ (IPCC 2006). In addition, the method considers forgone sequestration, i.e. the carbon sequestration avoided by the transformation of forest land.

Simplifying, the procedure can be described as follows: in the first step, the carbon content of the reference land use is calculated. On this basis, the carbon content of the projected land use is derived. Subsequently, the difference between both, i.e. the carbon content of the land use at the reference data and the projected land use is calculated and related to the functional unit. This includes the transformation of the calculated difference in carbon content to $\mathrm{CO}_{2}$ using the mole factor between $\mathrm{C}$ and $\mathrm{CO}_{2}$ (44/12), annualisation over a 20 -year period using a straight line discounting method and normalization to one $\mathrm{kg}$ output, i.e. putting the output in relation to the crop yield. The $\mathrm{CO}_{2}$ emissions from LUC evaluated through this method are well described by equation (1) (IPCC 2006) .

$$
C O_{2}{ }_{L U C_{-} k g c r o p}=\left[\frac{\left[\left(\Delta C_{B}-C_{S O I L S}\right) * \frac{44}{12} * 1000\right]+L_{\text {fire }}}{\left(Y_{P L U C} * \mathrm{t}\right)}\right] * 1000
$$

where $\mathrm{CO}_{2} \mathrm{LUC}$ kgcrop is the $\mathrm{CO}_{2}$ emission from LUC in $\mathrm{g} \mathrm{CO}_{2}$ per $\mathrm{kg}$ crop, $\triangle \mathrm{CB}$ is the change in carbon stocks in biomass, Csolls is the change in carbon stock in soil organic carbon, $44 / 12$ reflects the mole ratio of carbon to $\mathrm{CO}_{2}$, Lire is the amount of GHG emissions from fire, YPLUC is the annual yield of the projected land use and $t$ is the annualisation period, i.e. 20 years.

In the following we will exclusively focus on the further decomposition of $\Delta \mathrm{CB}_{\mathrm{B}}$ into its elementary parts (see equation (2), (3), and (4)). This highlights just a small snapshot of the overall equation system but provides a proper basis for the explanation of the simulation concept.

$$
\Delta C_{B}=\left[\left(A G B_{\text {Total }}+B G B_{\text {Total }}+D O M_{\text {Total }}+C_{\text {Foregone }}\right)-B_{f i r e}\right]-C_{G n}
$$

where $\triangle \mathrm{CB}$ is the change in carbon stocks in biomass, AGBтотAL is the total carbon content of AGB, BGBTotal is the total carbon content of BGB, DOMTOTAL is the total carbon content of DOM, CFOREgONE is the annual carbon sequestration avoided, B fire is the biomass carbon losses due to fire and CGn is the mean net increase in biomass carbon stocks due to biomass growth in the projected land use.

$$
B_{\text {fire }}=\left[A G B_{\text {Total }} * C_{f}\right]+\left[D O M_{\text {Total }} * C_{f}\right]
$$

where $C_{f}$ is the combustion factor.

$$
C_{G n}=A G B_{\text {Net }}+B G B_{\text {Net }}
$$




\section{Reinhard, Faist Emmenegger, Widok and Wohlgemuth}

where AGBNet is the carbon content of AGB of the projected land use. BGBNet is the carbon content of BGB on the projected land use. It is important to note that both terms reflect the difference between the annual gross carbon accumulation and the annual harvest in the projected land use, i.e. the net annual biomass growth.

In order to compute $\Delta \mathrm{CB}$, all equations must to be populated with the default values and parameters derived from the input data of the operator. The concept for doing so is explained in the following.

\subsection{Simulation model}

Our simulation transforms the bio-geographical condition parameters entered by the operator into the elementary expressions required for the computation of the equations used within the system. The required background data (parameters, default values) are stored in a MySQL database which is administered by a mix of php and drupal-proprietary syntax. The majority of the necessary data tables can be qualified under (i) tables necessary to store operator information / user data input tables and (ii) cross reference tables including parameters. The development of the database model was challenging given that the extensive background data of the IPCC had to be transformed, structured and normalized in the context of a relational database system. To give an idea of the required background data, $\sim 50$ out of the total $\sim 200$ relations in the database refer to the simulation of the emissions resulting from LUC.

The resulting benefit however is that a lot of the required computation is already implicitly embedded in the database structure, i.e. regulated by the distinct dependencies resulting from the normalized relations. For example, to distinctly identify the value for AGBTotal, the specification of the ecozone, the land use at reference date, the management practice, the continent, the canopy cover, the vegetation and the species type is required (Figure 4).

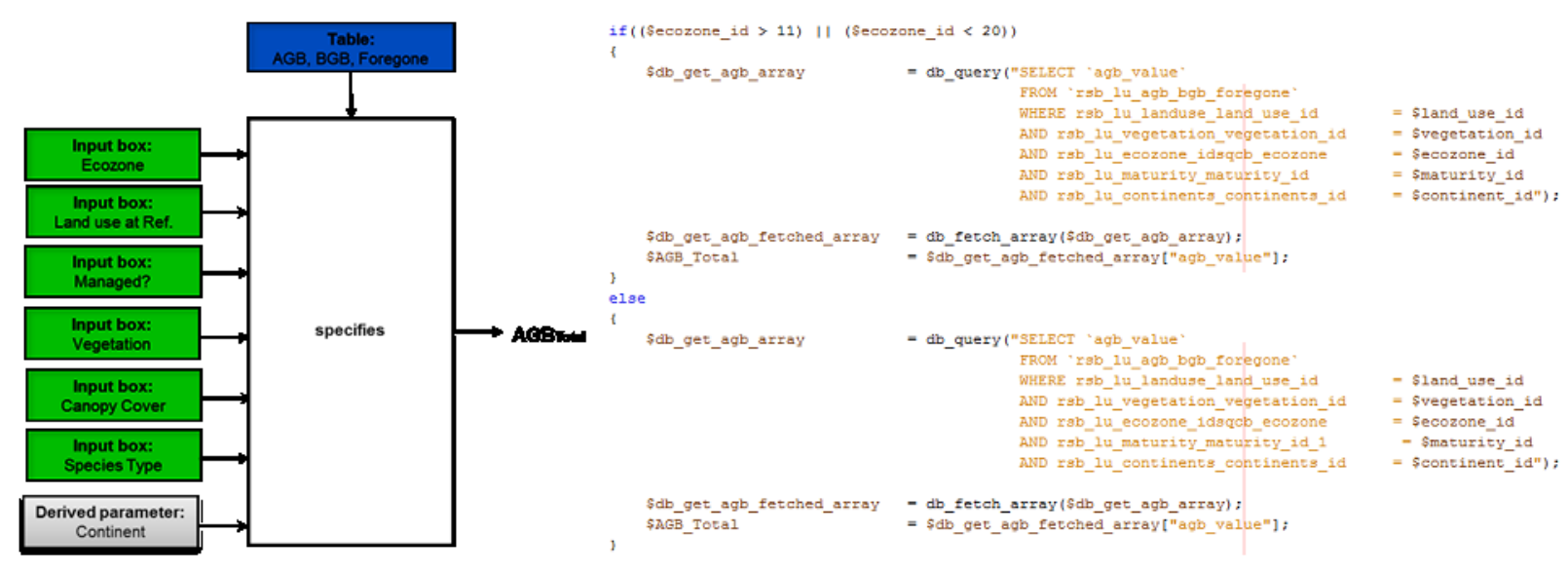

Figure 4: Input data required for the distinct identification of AGBTotal and exemplary DB Queries (source: own depiction).

Given that these dependencies are already reflected in the database structure, the simulation model was implemented by means of a few simple functions that use the context and input data of the operator to select all values required for the execution of the equation framework. Figure 5 shows the code for the calculation of the aggregated AGBTotal value. 


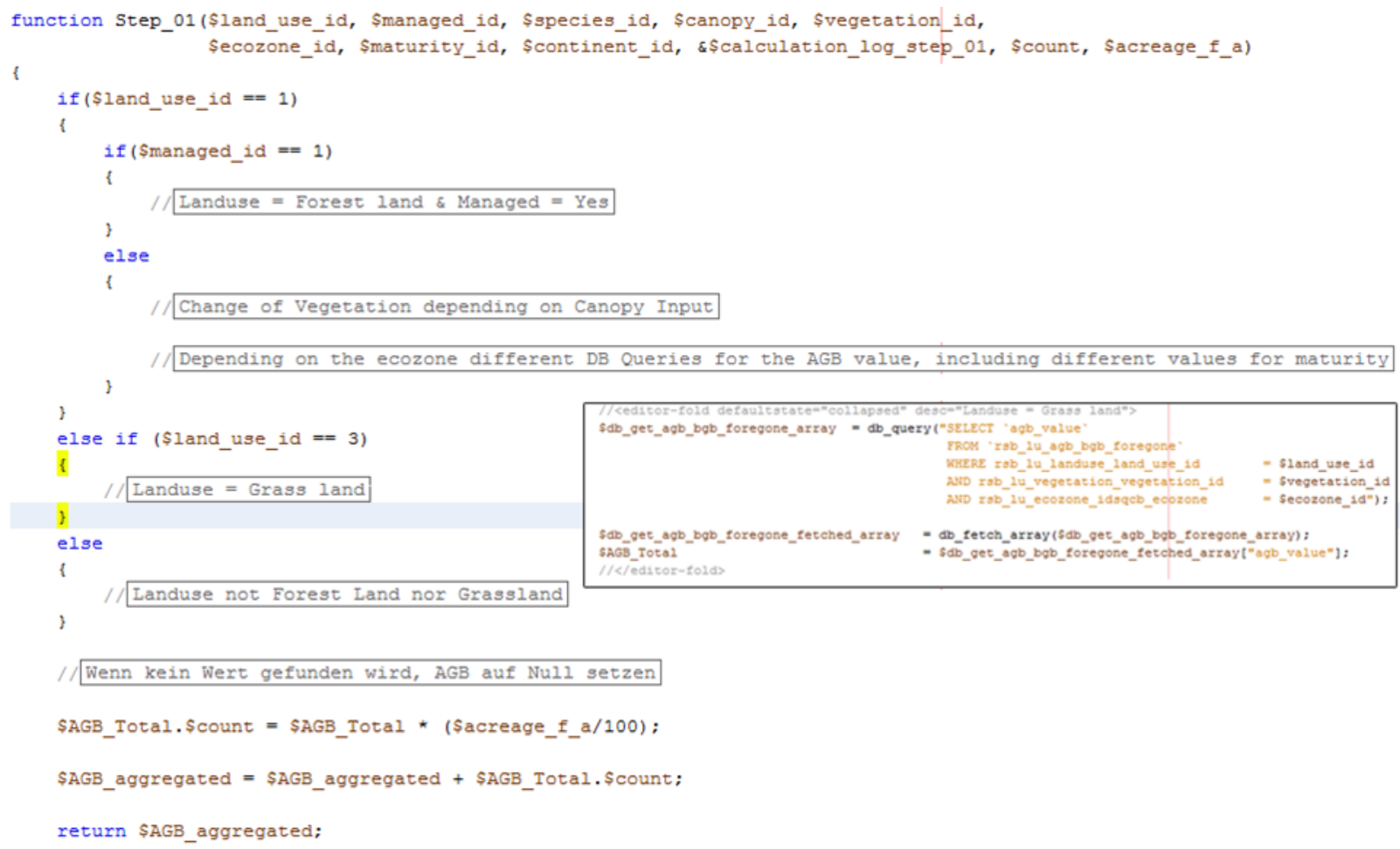

Figure 5: Code for the Calculation of the aggregated AGBTotal value (source: own depiction).

The calculation procedure of the LUC is unfolding stepwise, while step 1 refers to the calculation of the AGBTotal. Depending on the amount of land uses at reference date the actual value that is attributed to AGB is either an aggregated value of the AGB values from each land use at reference date multiplied by its acreage or just the value chosen from the database depending on the input choices considering the ecozone, the land use at reference date, the management practice, the continent, the canopy cover, the vegetation and the species type (see Figure 5 for reference).

\subsection{Results}

The simulation model delivers the $\mathrm{CO}_{2}$ and $\mathrm{N}_{2} \mathrm{O}$ emission associated with LUC according to the context and input data of the operator. To highlight the possible potential of such emissions, Figure 6 shows the Global Warming Potential (GWP 100) resulting from the transformation of rain forest to oil palm plantation in Malaysia in comparison with the GWP of the overall life cycle of palm methyl ester and the fossil reference. 


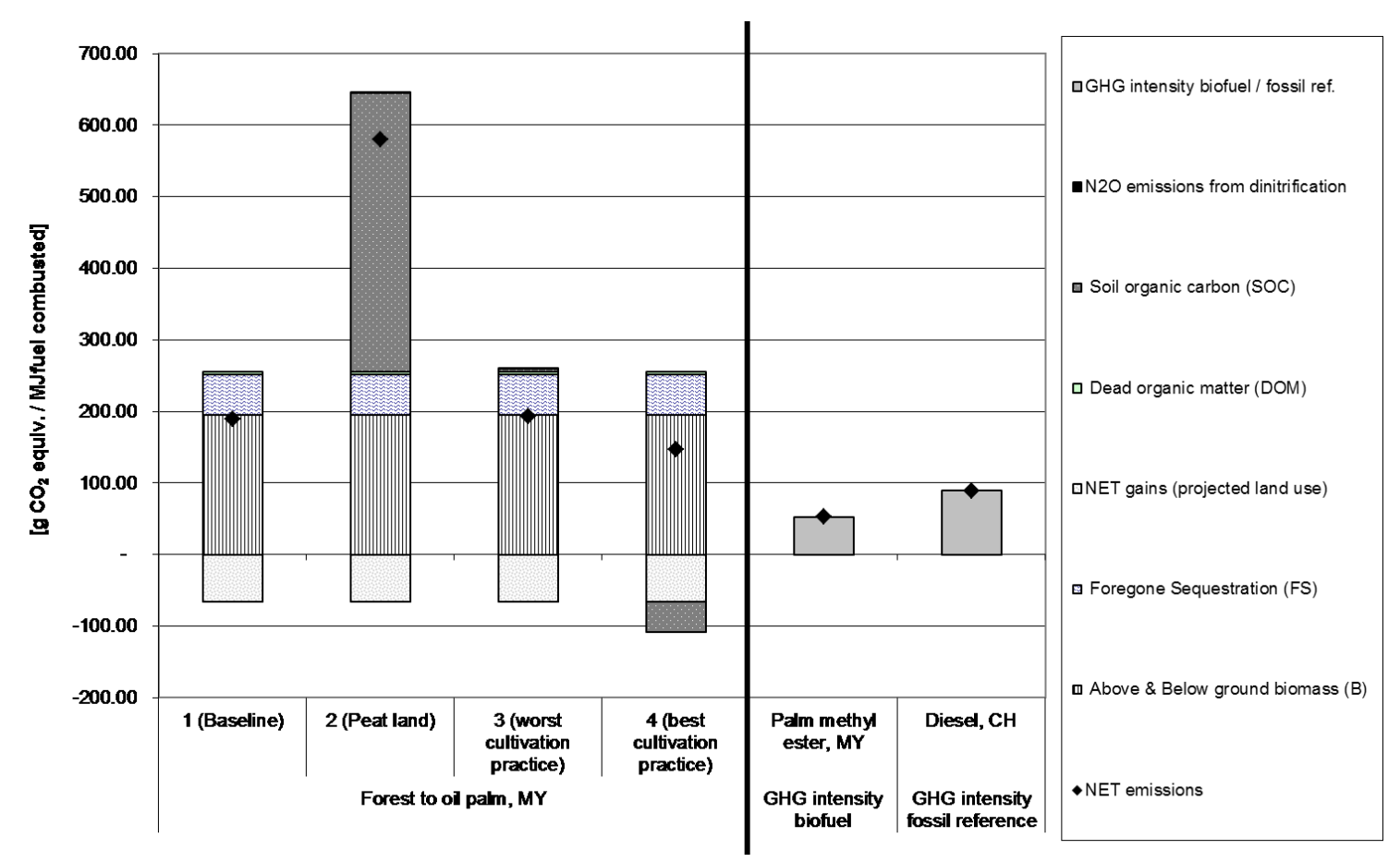

Figure 6. GHG emissions associated with the transformation of forest land to oil palm plantation. All results refer to the functional unit, i.e. $\mathrm{g} \mathrm{CO}_{2}$ equivalent/MJ fuel combusted (source: own depiction).

In general, the net GHG emissions of scenario 1 to 4 amount to $188,580,193$ and $147 \mathrm{~g} \mathrm{CO}_{2}$ equiv., respectively. The contributions of above ground biomass, foregone sequestration, dead organic matter and the net gains are the same for all scenarios, i.e. 195, 57, 3 and $-66 \mathrm{~g} \mathrm{CO}_{2}$ equiv., respectively. The negative GHG emissions associated with the net gains result from the fact that the increase (gain) in biomass on the projected land use is higher than the amount of biomass harvested for biofuel production.

In scenario 1 no emissions from soil organic carbon occur. When using default assumptions for management practice as here, the soil organic carbon content of the oil palm plantation equals the reference carbon content of natural forest. When the soil type is changed from mineral to organic soil (peat land), $\mathrm{GHG}$ emissions increase substantially, i.e. by $390 \mathrm{~g} \mathrm{CO}_{2}$ equiv., as shown by scenario 2. Scenario 3 and 4 show the effect of adapting to the worst resp. best cultivation practice, while the soil type is the same as in scenario 1. In the worst case, i.e. full tillage and no fertilizer input, $4 \mathrm{~g} \mathrm{CO}_{2}$ equiv. are added through emissions from soil organic carbon. The release of soil organic carbon is minor, given that only the factor for the input of fertilizer affects the decrease in soil organic carbon while both the factor for tillage and land use (tree crop) has no effect. In the best case, i.e. no tillage and high fertilizer input, $42 \mathrm{~g} \mathrm{CO}_{2}$ equiv. are accumulated in the soil. This means that due to sequestration, the soil organic carbon content of the oil palm system is higher than the soil organic carbon content of the natural system.

\section{DISCUSSION}

Emissions resulting from LUC can be of highest importance in the context of a biofuels GWP and can determine whether it complies with the threshold of a legislation / certification scheme or not. The presented simulation model allows the assessment and interactive analysis of the full range of emissions associated with land use change on a global scale. The backbone of the simulation model is its relational database system which supports an effective simulation procedure over the rather complex LUC model of the IPCC. 


\section{Reinhard, Faist Emmenegger, Widok and Wohlgemuth}

The LUC model of the IPCC and its inherent default values reflects a valid approach for the estimation of emissions from LUC. It captures the important dependencies and is, to our knowledge, the only model which provides a consistent set of default values and parameters which are applicable on a global scale. This focus, however, can be too coarse for certain regions. For that reason the operator always has the possibility to use own, context specific data for all relevant carbon pools.

In this regard, the simulation model would benefit from the integration of a Graphical Information Systems (GIS). Bio-geographical condition parameters such as soil type or ecozone could be directly stored in GIS layers and accessed on the basis of the location of the cultivation area. This would reduce the amount of context specific data required from the operator and provide the basis for the implementation of a higher regional resolution.

\section{CONCLUSION}

Because of the complexity of the LUC model of the IPCC, it is of high importance that the simulation of emissions from LUC is standardized in a tool which can be handled by novice in the field of LUC assessment. This is also true for the rest of the simulation modeling in the life cycle of biofuels.

The RSB GHG module allows the interactive assessment of the GHG emissions of specific steps of biofuels pathways without conducting a time and resource-intensive life cycle assessment study. It is based on state-of-the-art Life Cycle Inventory (LCI) models and applies common accepted evaluation schemes for the GHG assessment of biofuels. Because the results are calculated immediately, the RSB tool can be used interactively. The user can observe the impact of each LCI flow and get insights on the hot spots within the scope of his production step. This enables the operator to understand the influence and interaction of different decisions and factors on the environmental performance under his scope of operation.

The RSB tool is publicly available and allows an operator, apart from the calculation of GHG emissions, to also assess the sustainability of a biofuel of interest with respect to the RSB requirements. In doing so it increases the knowledge on critical issues in agro-biofuel production thus representing an important cornerstone for the implementation of more sustainable biofuel pathways.

\section{ACKNOWLEDGEMENT}

We are grateful to Victoria Junquera from the Roundtable on Sustainable Biofuels (RSB) and Rainer Zah from the Life Cycle Assessment and Modeling (LCAM) group who contributed to an early version of this paper. Moreover, we are thankful to the Swiss State Secretary of Economic Affairs (SECO) for the funding of the project.

\section{REFERENCES}

Bauen, A., P. Watson, et al. 2007. Carbon Reporting within the Renewable Transport Fuel Obligation Methodology, E4TEch: 37.

CARB 2009. Californian Low Carbon Fuel Standard. Resolution 09-31. S. o. California. Sacramento: 19.

Dehue, B., C. Hamelinck, et al. 2007. sustainability reporting within the RTFO: Framework Report. RTFO, Ecofys: 83.

EPA 2010. Regulation of Fuels and Fuel Additives: Changes to Renewable Fuel Standard Program: Final Rule, Environmental Protection Agency. 75: 14669-15320.

Fargione, J., J. Hill, et al. 2008. "Land Clearing and the Biofuel Carbon Debt." Science 319(5867): 1235 1238.

Farrell, A. E., R. J. Plevin, et al. 2006. "Ethanol Can Contribute to Energy and Environmental Goals." Science 311: 506-508.

Finnveden, G., M. Z. Hauschild, et al. 2009. "Recent developments in Life Cycle Assessment." Journal of Environmental Management 91(1): 1-21. 


\section{Reinhard, Faist Emmenegger, Widok and Wohlgemuth}

Guinée, J. B. 2001. Life Cycle Assessment: An operational guide to the ISO standards. L. U. Centre of Environmental Science, The Netherlands: 19.

IEA 2007. Potential Contribution of Bioenergy to the World's Future Energy Demand. Paris, IEA Bioenergy: 12.

IPCC 2006. IPCC Guidelines for National Greenhouse Gas Inventories. Hayama, Japan, Institute for Global Environmental Strategies.

Leuenberger, M. and A. Huber-Hotz 2006. Botschaft zur Änderung des Mineralölsteuergesetzes. Bern: 30.

Rebitzer, G., T. Ekvall, et al. 2004. "Life cycle assessment: Part 1: Framework, goal and scope definition, inventory analysis, and applications." Environment International 30(5): 701-720.

Reinhard, J. and R. Zah 2009. "Global environmental consequences of increased biodiesel consumption in Switzerland: consequential life cycle assessment." Journal of Cleaner Production 17(Supplement 1): S46-S56.

RSB 2008. Roundtable on Sustainable Biofuels: Global Principles and criteria for sustainable biofuels production. Version Zero. Lausanne, EPFL: 12.

Schaltegger, S. 1996. Life Cycle Assessment (LCA) - Quo vadis? Berlin, Birkenhäuser Verlag.

Scharlemann, J. P. W. and W. F. Laurance 2008. "How green are biofuels?" Science 319: 43-44.

Searchinger, T., R. Heimlich, et al. 2008. "Use of U.S. Croplands for Biofuels Increases Greenhouse Gases Through Emissions from Land Use Change." Science 319(5867): 1238 - 1240.

TC383 2009. CEN-TC383: sustainably produced biomass for energy applications. E. C. $f$. Standardization. Brussels.

Tillman, A.-M. 2000. "Significance of decision-making for LCA methodology." Environmental Impact Assessment Review 20(1): 113-123.

Weidema, B. P., C. Bauer, et al. 2011. Overview and methodology: Data quality guidelines for the ecoinvent database version 3. St. Gallen, ecoinvent. No. 1.

Wohlgemuth, V. 2005. Komponentenbasierte Unterstützung von MEthoden der Modellbildung und Simulation im Einsatzkontext des betrieblichen Umweltschutzes. Konzeption und prototypische Entwicklung eines Stoffstromsimulators zur Integration einer stoffstromorientierten Perspektive in dei auftragsbezogene Simulationssicht. Aachen, Shaker Verlag.

Zah, R., M. Faist, et al. 2009. "Standardized and simplified life-cycle assessment (LCA) as a driver for more sustainable biofuels " Journal of Cleaner Production: S102-S105.

Zah, R., R. Hischier, et al. 2007. Life Cycle Assessment of Energy Products: Environmental Impact Assessment of Biofuels. Bern, Bundesamt für Energie, Bundesamt für Umwelt, Bundesamt für Landwirtschaft: 151.

\section{AUTHOR BIOGRAPHIES}

JÜRGEN REINHARD is a research associate in the group Life Cycle Assessment and Modeling (LCAM) at the Swiss Federal Laboratories for Materials Science and Technology (Empa) since May 2008. He received his master's degree in Industrial Environmental Informatics from the University of Applied Sciences (HTW) in Berlin. His current research interests are in spatial Life Cycle Assessment and software development. Jürgen Reinhard is currently doing a second Master (Fast Track) in Information Systems at the University of Zurich and plans to do a PhD in the field of environmental informatics. His email address is juergen.reinhard@empa.ch.

MIREILLE FAIST EMMENEGGER has graduated at the ETH Zürich / EAWAG with a PhD in the field of material flux analysis in the group of Prof. Peter Baccini. After 6 years as a project leader in a consultancy firm specialized in LCI and LCA, she moved to Empa (Swiss Federal Laboratories for Materials Testing and Research) as a research fellow, in the Technology \& Society Lab since 2008; her work area is Life Cycle Assessment and Life cycle inventories, with a focus on biofuels and tex- 
tiles. She is also a member of the Editorial Board of ecoinvent (www.ecoinvent.org). Her email address is mireille.faist@empa.ch.

ANDI H. WIDOK studied Industrial Environmental Computer Science at the HTW Berlin, University of Applied Sciences. He holds a (M.Sc.) degree in Industrial Environmental Computer Science and works as a research assistant at the HTW Berlin. In 2011 he became a PhD student of the University of Hamburg. His research interest are mainly sustainability theory and its appliances in computer simulations, cooperative model building, and sustainable software development for organizations. His email isa.widok@htw-berlin.de.

VOLKER WOHLGEMUTH studied Computer Science at the Universities of Hamburg and Canterbury, Christchurch, New Zealand. He got his PhD in 2005. Since 2005 he is working as a professor for Industrial Environmental Informatics at the HTW Berlin, University of Applied Sciences. His research fields are material flow management, modeling and simulation business systems and Environmental Management Information Systems (EMIS). His email is volker.wohlgemuth@htw-berlin.de. 